\title{
Coronary artery spasm: mimicry, misdiagnosis and misfortune
}

\author{
Hazlyna Kamaruddin, ${ }^{1}$ Rachel Orme, ${ }^{1}$ Ian R Hall, ${ }^{1}$ Julian Gunn ${ }^{2}$
}

${ }^{1}$ Department of Cardiology, Sheffield Teaching Hospitals NHS Trust, Sheffield, UK ${ }^{2}$ Cardiovascular Research Unit, Sheffield Teaching Hospitals and University of Sheffield, Sheffield, UK

\section{Correspondence to} Dr Hazlyna Kamaruddin, hazlyna@hotmail.com

Accepted 26 February 2015
CrossMark

\footnotetext{
To cite: Kamaruddin $\mathrm{H}_{\text {, }}$ Orme R, Hall IR, et al. BMJ Case Rep Published online: [please include Day Month Year] doi:10.1136/bcr-2014204519
}

\section{DESCRIPTION}

A 51-year-old man with a history of ischaemic heart disease (IHD), previous percutaneous coronary intervention (PCI) and rheumatoid disease, presented with chest pain and inferoposterior ST segment elevation in August 2013. He had continued to smoke after his diagnosis of IHD and PCI.
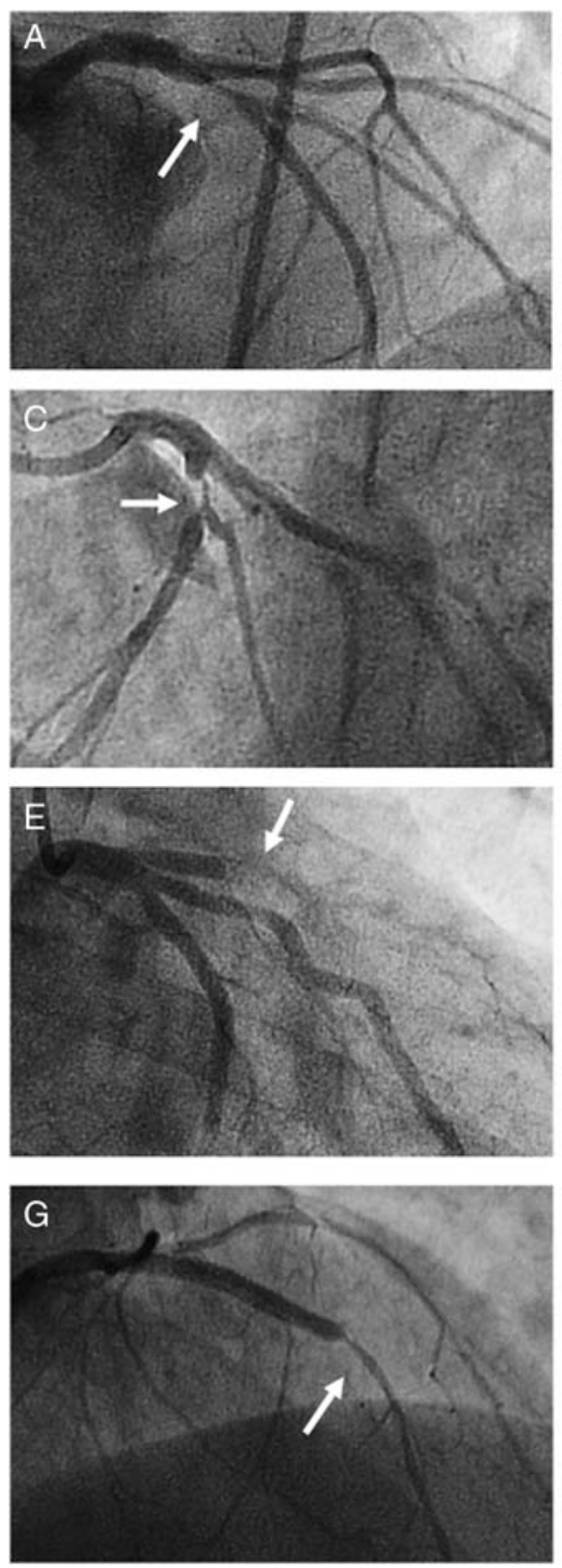

In 2006, he presented with an acute coronary syndrome (ACS) and had a significant left anterior descending artery (LAD) stenosis, which was treated with one stent (figure 1A, B). He presented again in 2007 with in-stent restenosis, and a second stent was implanted (figure 1C, D). In April 2013, he had an emergency presentation
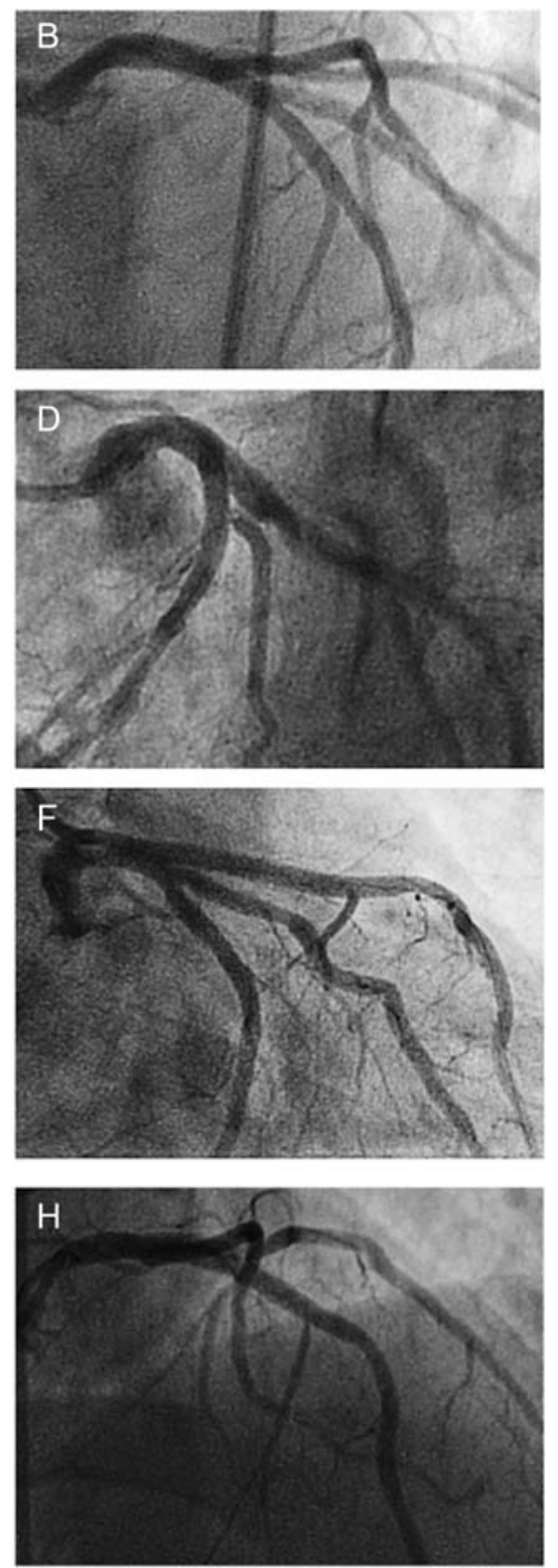

Figure 1 Coronary angiogram showing significant stenosis of the proximal portion of the left anterior descending (LAD) at initial presentation in 2006 with ST elevation myocardial infarction (A) and, in 2007, with in-stent restenosis (C), both showing good angiographic results after stent implantation (B and D). In-stent thrombosis in early 2013 showing completely occluded $\mathrm{LAD}(\mathrm{E})$, again treated with another stent implantation $(\mathrm{F})$. Left coronary artery in the most recent angiogram from August 2013 showing a widely patent stent but widespread spasm in other vessel including the branches $(G)$, which returned to normal calibre after intracoronary nitrate $(H)$. 
with stent thrombosis and a third stent was implanted in the LAD (figure $1 \mathrm{E}, \mathrm{F}$ ).

When the patient presented again in August 2013, coronary angiography revealed widely patent proximal stents, but the remainder of the $\mathrm{LAD}$ and all of its branches were in spasm (figure $1 \mathrm{G}$ ).

The images from the previous interventions were reviewed; the calibre of the coronary arteries at the end of the procedures had dramatically increased compared with baseline (figure 1B, $\mathrm{D}, \mathrm{F})$. A diagnosis of coronary artery spasm was made and intracoronary nitrate administered. The vasospasm resolved and the arteries returned to their full size with no intervention required (figure $1 G$ ).

Review of the patient's medication history revealed that in 2013, following stent thrombosis, his regular calcium channel blocker was stopped and substituted with a $\beta$-blocker. He was restarted on a vasodilating calcium channel blocker during this admission and to date no further problems have ensued.

Focal coronary artery spasm due to coronary artery smooth muscle hyperactivity has been well described, especially following delivery of a drug-eluting stent. ${ }^{1}$ A more diffuse spasm in all the epicardial arteries is less common and likely to be a consequence of diffuse endothelial dysfunction from several factors, ${ }^{2}$ in this case smoking and rheumatoid arthritis.

A diffuse spasm in all the epicardial arteries is less common than focal coronary artery spasm, and is likely to be a consequence of diffuse endothelial dysfunction from several factors, ${ }^{1}$ in this case smoking and rheumatoid arthritis. Although $\beta$-blockers are used in coronary artery spasm, their use can be detrimental, ${ }^{2}$ so early recognition of this phenomenon is important to ensure appropriate treatment. Calcium channel blockers remain the mainstay in the treatment of coronary artery spasm. ${ }^{3}$

\section{Learning points}

- Coronary artery spasm can mimic coronary artery stenosis due to atherosclerotic plaque, and may result in unnecessary stent implantation.

- Endothelial dysfunction, in this case a pre-existing rheumatoid disease, is likely the pathophysiology of the widespread coronary artery spasm despite stent implantation in the affected segment at initial presentation.

- Calcium channel blockers should be continued in patients with previous history of diffuse coronary artery spasm.

Contributors HK and IRH were involved in the care of the patient. HK prepared and edited the whole manuscript. RO, IRH and JG edited the manuscript and the images.

Competing interests None.

Patient consent Obtained.

Provenance and peer review Not commissioned; externally peer reviewed.

\section{REFERENCES}

1 Mahemuti A, Abudureheman K, Schiele F, et al. Association between inflammatory markers, hemostatic markers, and traditional risk factors on coronary artery spasm in patients with normal coronary angiography. I Interv Cardiol 2014;27:29-35.

2 Cannon CP, Braunwald E. Unstable angina and non-ST elevation myocardial infarction. In: Libby P, Bonow RO, Mann DL, Zipes DP. eds. Braunwald's heart disease. 8th edn. Philadelphia, PA: Saunders Elsevier, 2008:1319-51.

3 Stern S, Bayes de Luna A. Coronary artery spasm: a 2009 update. Circulation 2009;119:2531-4.

Copyright 2015 BMJ Publishing Group. All rights reserved. For permission to reuse any of this content visit http://group.bmj.com/group/rights-licensing/permissions.

BMJ Case Report Fellows may re-use this article for personal use and teaching without any further permission.

Become a Fellow of BMJ Case Reports today and you can:

- Submit as many cases as you like

- Enjoy fast sympathetic peer review and rapid publication of accepted articles

- Access all the published articles

- Re-use any of the published material for personal use and teaching without further permission

For information on Institutional Fellowships contact consortiasales@bmjgroup.com

Visit casereports.bmj.com for more articles like this and to become a Fellow 